\title{
COMMISSION 10: SOLAR ACTIVITY (ACTIVITE SOLAIRE)
}

\section{COMMISSION 12: SOLAR RADIATION AND STRUCTURE \\ (RADIATION ET STRUCTURE SOLAIRE)}

\author{
Report of Meetings, 20 and 23 August, 1994 \\ PRESIDENT (10): V. Gaizauskas \\ PRESIDENT (12): J. O. Stenflo \\ SECRETARY (10): O. Engvold
SECRETARY (12): F.-L. Deubner
}

This report was prepared jointly by Commissions 10 and 12 and reflects the combined nature of their activities during the 22nd General Assembly. Members of Commission 49 (The Interplanetary Plasma and The Heliosphere) were invited to attend both business meetings (20 August 11:00 - 12:30 and 23 August 11:00 - 12:30) since a merging of all three solar commissions into a single body was under discussion. A separate report is filed by Commission 49 in these Transactions.

\section{Reorganization of the IAU}

The first item discussed at the business meeting on August 20 was the proposed reorganization of the IAU and its implications for solar physics. The discussion provided guidance for the negotiating position to be taken by Presidents of solar commissions at the decisive meeting on August 22 of the IAU Executive Committee (EC) with all the Commission Presidents and Vice Presidents. The second business meeting, on August 23, began with an account of the outcome of the August 22 meeting, followed by a discussion of the consequences the new Division structure will have on the work of solar physics within the IAU.

J.O. Stenflo chaired the restructuring discussions; he started with a brief overview on the evolution of the restructuring concepts over the past three years. The original idea of the EC was to have a concerted merger of various commissions, so that the total number of commissions would be reduced from 40 to about 14 , one of which would deal with the Sun. After contacts with Commission 49 (The Interplanetary Plasma and the Heliosphere) and consultation with our commission members, the three commissions 10,12 , and 49 agreed to be willing to merge into a single new commission with the name "The Sun and the Heliosphere". They however made it clear to the IAU General Secretary that a necessary condition for their merger was for it to take place within the framework of a general overhaul of the IAU. A partial restructuring of the IAU would not suffice.

As it turned out in a Special Meeting of the EC and all Presidents and Vice Presidents on 19 August, most of the other IAU commissions were unwilling to merge at all. The idea of a concerted merger was therefore dropped by the EC; a divisional structure was proposed instead and it was formally adopted at the meeting of 22 August. The various commissions may continue their existence and work in the same manner as before, but will be grouped in Divisions. The final proposal by the EC comprised 11 Divisions, where the second Division has the name "Sun and Heliosphere", representing the grouping of Commissions 10, 12, and 49 with a total of 763 members. The Board of this Division consists of the 6 Presidents and Vice Presidents of the three member commissions. The Board elects its own Chairman, who will officially represent the Division through interactions with the EC. The form of the relation between the Division heads and the Executive Committee could however not be decided on during the course of the General Assembly. 
The negotiating position that had been taken by the Presidents of the solar commissions was unanimously endorsed by the participants of our business meetings. The proposed divisional structure of the IAU was welcomed and fully supported. It was felt that the number of proposed divisions was appropriate but should not be increased, and that the Sun and Heliosphere were represented in a fair and adequate way in the new structure. No dissenting voices were raised.

\section{Working Groups of the Commission(s).}

V. Gaizauskas chaired the portions of both business meetings which were concerned with the formation of Working Groups. He reviewed the rationale for involving more Commission members, not just the Organizing Committee, in activities which are relevant to the broad aims of the IAU: coordinating collaborative programs of observations; establishing standards for data acquisition in order to facilitate exchanges of data; supporting the compilation and publication of key archives of data in innovative formats made possible by new technologies. Broader involvement is seen as essential in the new enlarged structure of solar commissions in order to manage it and to be responsive to practical issues affecting our discipline. A newsletter circulated to members of Commission 10 in July 1994 contained specific suggestions for Working Groups or panels to deal with some of these issues.

\subsection{WORKING GROUP ON THE SOLAR CYCLE AND SOLAR VARIABILITY}

During IAU Colloquium 141 in June 1993, the Scientific Organizing Committee expressed its concern in a letter to the IAU General Secretary that basic questions about long-term solar variability remain in limbo because space agencies are unwilling to re-fly the same radiometric experiments, even with upgraded equipment. Although this concern elicited sympathetic responses from several space agencies, the international implications were believed to be serious enough to warrant formation of a long-term pressure group in the solar commissions which would monitor all aspects of this issue. An Ad Hoc Committee was therefore asked to determine whether a new Working Group of the IAU should be formed on Solar-Stellar Irradiance Variability. It was chaired by $O$. $R$. White and included C. Frohlich, V. Gaizauskas, D. F. Gray, H. S. Hudson, W. Kalkofen, J. Kuhn, J. Pap, C. J. Schrijver, K. Shibata, G. F. Sitnik, J. O. Stenflo, J.-C. Vial, R. C. Willson. A specific proposal from the Ad Hoc Committee was circulated to Commission 10 members in July 1994. Over one dozen e-mail responses supported the broad objectives of the proposal. The discussion at the business meeting on 20 August was also in favour, but objections were raised that, in its most recent form, the scope of the proposal had become too broad. It was recommended that the Ad Hoc Committee revise the proposal to have sharper directives which would take account of aims of existing programs such as RISE (Radiative Inputs from the Sun to the Earth).

\subsection{DATA ARCHIVING}

New technology is making large pools of solar digital data accessible from remote sites. But what are the standards for calibrating these data, for cataloging and displaying them efficiently? Should there be a permanent Working Group assigned to set these standards? It was agreed that these problems would best be addressed at an IAU colloquium organized especially for this purpose.

\subsection{NOMENCLATURE}

Misunderstandings and conflicts have come to the attention of the President of Commission 10 arising from misinterpretation of terminology in widely circulated publications of data on solar activity. No thorough review has been made of solar nomenclature in nearly two decades even though many new phenomena have been discovered during that time. There are at least two requirements: to define 
standard terms applied to compilations of data; to assign descriptors to phenomena that are acceptable to observers and theorists alike. There was general agreement that either a panel or Working Group should be set up to conduct this review.

\section{Election of Commission officers and new Organizing Committees}

The following persons were ratified by members in attendance as officers and members of the new Organizing Committees for 1994-7: for Commission 10, O. Engvold (President), Ai Guoxiang (Vice President), V. Gaizauskas (Past President), A.O. Benz, A. Bhatnagar, R.A. Harrison, K.L. Harvey, S.W. Kahler, I.S. Kim, T. Kosugi, F. Moreno-Insertis, G. Poletto, M. Rovira, B. Schmieder, C.J. Schrijver, J. Sylwester; for Commission 12, F.-L. Deubner (President), P. Foukal (Vice President), J.O. Stenflo (Past President), M. Collados, Fang Cheng, R. Hammer, F. Hill, V. Makarov, C. Marmolino, R. Rutten, 'T. Sakurai, P. Venkatakrishnan.

A discussion ensued concerning the lack of female representation for Commission 12. Several alternative names were proposed which, however, had to be rejected since they were not members of Commission 12. It was agreed to accept the proposed list as it was, but the new Organizing Committee was instructed to find ways to attract more female IAU members with an interest in the sun to become members of Commission 12.

Immediately following the last business meeting the attending new Presidents and Vice Presidents of Commissions 10, 12, and 49 met to constitute the Board of the Division "Sun and Heliosphere". They elected as Division Chairman the new President of Commission 10, O. Engvold.

\section{Reports of the WG on Eclipses and of Representatives of International Programs}

\section{1 WORKING GROUP ON SOLAR ECLIPSES}

The Chairman of the Working Group, J. Pasachoff, reported on plans for observations by professional istronomers of the 3 November 1994 total solar eclipse. Totality will be visible from a path that crosses parts of Peru, Chile, Bolivia, Paraguay, Argentina, and Brazil. Weather forecasts are best for the high desert of Chile and Bolivia, where totality will last about 3 minutes. Pasachoff reported on a site survey he made in October/November 1993 to Putre, Chile (3500 m altitude), and to Potosi, Bolivia (4000 $\mathrm{m}$ altitude), and nearby locations, as well as on possible sites for professional and other eclipse parties. He discussed the arrangements made for a joint IAU-UAI site for professional astronomers in Putre and also discussed sites in other countries, notably Brazil. His work is supported in part by NSF grant ATM-9207110 and by National Geographic Society grant 5190-94.

The eclipse of 24 October 1995 crosses Iran, Afghanistan, Pakistan, India, Bangladesh, Myanmar, Thailand, Cambodia, Vietnam, Sabah (Malaysia), and islands of the Philippines and Malaysia. The most favorable weather forecasts are for India.

Fred Espenak (NASA Goddard Space Flight Center) and Jay Anderson (Prairie Weather Centre, Canada) are preparing NASA Reference Publications about each eclipse. They can be found on the World Wide Web at http://umbra.gsfc.nasa.gov/sdac.html.

\subsection{QUARTERLY BULLETIN ON SOLAR ACTIVITY (QBSA)}

The report written by $T$. Hirayama, chief editor of the QBSA, indicates that the backlog of flare reports has been reduced significantly; the compilation of solar radio emission remains in arrears because considerable manpower was diverted to completion of the Nobeyama radioheliograph. The other 3 sections of the QBSA, sunspots, synoptic magnetic charts, and intensity of coronal emission, are on schedule. T. Sakurai becomes the chief editor in April, 1995. P. Lantos (Meudon) serves as IAU representative for the new triennium to the directing board for the QBSA. 


\subsection{SUNSPOT INDEX DATA CENTRE (SIDC)}

The SIDC network contributing to the production of the Provisional Sunspot Number now consists of 120 stations (42 professional and 78 amateurs). A new major activity added to many other services provided by the SIDC is the preparation of hemispheric sunspot numbers, i.e. separate daily numbers for the northern and southern hemispheres of the Sun. P. Cugnon directs the work of the SIDC since the retirement of A. Koeckelenbergh in February, 1994

\subsection{DEBRECEN PHOTOHELIOGRAPHIC RESULTS (DPR)}

The written report on the status of the DPR prepared by L. Dezsơ was presented to the meeting with emphasis on the following main points:

- the DPR volume for 1978 is ready for publication, but printing and distribution costs would consume almost the entire subvention from IAU-ICSU;

- an alternative to printing the Results is to apply the grant (US\$5000) to the purchase of a higher speed, higher capacity computer for accelerating data reduction and for making the Results available on electronic media;

- software and manpower from the Kanzelhöhe Observatory are available for assisting the Debrecen group to upgrade their reduction procedures;

- it is intended that L. Dezsö and A. Kovacs continue and finish the years 1979 to 1985 (i.e. Cycle 21) to the level of detail provided in the already published 1977 Results;

- an independent team at Debrecen headed by B. Kalman will take responsibility for data from 1986 onwards; they intend to produce Results with less day-to-day detail and to post them on an electronic bulletin board.

A resolution was submitted to the EC in support of the revised position at Debrecen (see item 5.2).

\subsection{INTERNATIONAL URSIGRAM AND WORLD DAYS SERVICE (IUWDS)}

H. Coffey, IAU representative to IUWDS, reported on activities for the past 3 years. IUWDS is a permanent service of URSI, IAU, and IUGG which alerts the world scientific community about transient solar-geophysical events and which helps to coordinate scientific observations that cannot be carried out continuously. It accomplishes this program by preparing an annual International Geophysical Calendar with a list of "World Days", by providing an International Ursigram Service to alert those requiring experimental data during a specific state of solar, ionospheric, or magnetospheric activity, and by arranging Solar-Terrestrial Predictions Workshops. The proceedings of the most recent Workshop (held in Ottawa, 1992) were published early in 1994; an offer from Japan to host the next meeting (1996) has been accepted. A new IUWDS Code Book was prepared in 1993 for compressing observational data into a computer readable format. There has been a marked increase for making data, including daily X-ray images of the Sun from the Yohkoh satellite, available on electronic bulletin boards, both from IUWDS and non-IUWDS sources. Discussions are taking place to increase membership of IUWDS to include a wider geographical spread, in particular to South America and South Africa. H. Coffey agreed to continue as IAU representative to IUWDS.

\subsection{FEDERATION OF ASTRONOMICAL AND GEOPHYSICAL DATA ANALYSIS SERVICES (FAGS)}

E. Tandberg-Hanssen, president of FAGS, explained the role of FAGS in supporting the activities of twelve astronomical and geophysical services, including IUWDS, QBSA, and SIDC. In order to streamline the allocation of funds, and to bring the Debrecen Photoheliographic Results under the umbrella of FAGS, it was suggested that a single directing board be established for the solar-related 
services called the International Service for Solar Activity (ISSA). Recommendations from this body would be used by FAGS to decide the allocation of funds among the solar bulletins. A possible composition of the ISSA would include the directors of the solar bulletins, the heads of World Data Centres (or their delegates) at Boulder, Meudon, Moscow, Beijing, and Tokyo, as well as two representatives of the 'user' community, one of whom would serve as chairperson. The proposal to form the ISSA was communicated to the EC as a letter and subsequently approved.

\subsection{SCIENTIFIC COMMITTEE ON SOLAR-TERRESTRIAL RESEARCH (SCOSTEP)}

S. T. Wu reported that the SCOSTEP Bureau has established two sub-committees to plan a new range of activities as STEP (Solar-Terrestrial Energy Program) winds down in 1995: (1) to plan a 5-year post-STEP analysis project (Results from Analyses and Modeling Program, or RAMP); (2) to review all post-STEP proposals for new projects and to recommend their implementation. In response to these moves, V. Obridko and colleagues in Moscow propose an International Decade of Solar Cycle Studies. A summary of their proposal was presented to the meeting; a supporting draft resolution was approved with modifications and forwarded to the EC (see item 5.1). B. Schmieder will serve as IAU representative to SCOSTEP for 1994-1997.

\section{RESOLUTIONS}

5.1. The following resolution put forward by V. Obridko was adopted by the business meeting of Commissions 10 and 12 and, subsequently, by the General Assembly:

Taking into account that,

previous long term solar programs focused mainly on the years around minimum or maximum, and did not cover a full cycle for observing solar-terrestrial phenomena, whereas understanding solar cyclic periodicity requires a study of its various manifestations over an entire activity cycle,

and that,

space missions (e.g. SOHO) and major ground-based projects (GONG) planned for the late 1990 's into the early 2000's promise important achievements in solar-terrestrial studies,

and that,

according to its Constitution, one of the main tasks of SCOSTEP is to organize and to coordinate STP programs of interest to, and approved by, at least two of the ICSU Participating Bodies,

IAU as one of the Participating Bodies,

adopts the proposed project with the preliminary name IDSCS - International Decade of Solar Cycle Studies - aimed at the study of specific solar-terrestrial phenomena during the entire 23rd solar cycle, with special emphasis during the main phases of the cycle,

and recommends that SCOSTEP take all necessary actions to organize the Project for the term 1997-2007.

5.2. The following resolution was received by the EC of the IAU but not adopted, pending negotations with ICSU on redefining the purpose of the grant to Debrecen. 
IAU Commission 10 (Solar Activity),

having received an extended report from Prof. L. Dezso on the deteriorating situation regarding the reduction and the publication of the Debrecen Photoheliographic Results, and noting with concern that, under the present economic situation of Hungary in general and of the Debrecen Observatory in particular, publication of the DPR cannot be supported financially from Hungarian sources,

endorses the recommendation by the Board of the Joint Organization for Solar Observations (JOSO) that the DPR be published henceforth by electronic means beginning with the year 1978 which has been compiled but not yet printed,

and requests the IAU and ICSU to agree that the amount of US\$5,000 already granted by ICSU be applied not to the printing of the DPR, but to the provision of a faster computer and frame grabber in order to speed up the basic measurements and the data analysis and to enable a transfer of the reports to an electronic bulletin board.

\section{Commission Membership}

J.O. Stenflo read the names of the deceased members of Commissions 10,12, and 49 . The meeting participants rose to honor the deceased members with a moment of silence. 